\section{Implant-Supported Removable Partial Denture Improves the Quality of Life of Patients with Extreme Tooth Loss}

\author{
Camila Heitor Campos, Thais Marques Simek Vega Gonçalves, Renata Cunha \\ Matheus Rodrigues Garcia
}

Department of Prosthodontics and Periodontology, Piracicaba Dental School, UNICAMP - University of Campinas, Piracicaba, SP, Brazil

Correspondence: Renata Cunha Matheus Rodrigues Garcia, Avenida Limeira, 901, Bairro Areião, 13414-903 Piracicaba, SP, Brasil. Tel: +55-19-2106-5240. e-mail: regarcia@unicamp.br

\begin{abstract}
This study aimed to evaluate oral health-related quality of life (OHROoL) in partially dentate subjects, presenting extreme tooth loss in posterior region with missing postcanines, comparing the use of conventional removable partial dentures (RPDs) and implant-supported RPDs. OHRQoL was measured using the Brazilian version of the Oral Health Impact Profile. Twelve subjects presenting maxillary total and mandibular Kennedy Class I edentulism (mean age $62.6 \pm 7.8$ years) first received complete maxillary dentures and conventional mandibular free-end RPDs. After two months, the subjects had their OHROoL assessed. Osseointegrated implants were inserted bilaterally in the mandibular first molar regions, and after four months ball abutments were placed to support the free-end RPD. Two months later, the patients had their OHROoL reassessed. Wilcoxon signed-rank test was used to evaluate differences in OHROoL $(\alpha=0.05)$. Results showed improvement in all OHIP-49 domains $(p<0.05)$ after associating implants to the RPD. The mandibular implant-supported free-end RPD significantly improved OHROoL.
\end{abstract}

\begin{abstract}
Key Words: quality of life, removable partial denture, prostheses and implants, implant-supported dental prosthesis, tooth loss.
\end{abstract}

\section{Introduction}

Public health programs and development in technology have contributed to a decrease in edentulism worldwide; yet tooth loss is still a reality (1). In this context, the number of partially edentulous individuals requiring prosthetic treatment has been increasing (1). Since tooth loss can affect different aspects of patient's life including appearance, phonetics and masticatory function (2), it may have a consequence in patient's quality of life and general health $(2,3)$.

Partial tooth loss can be treated using different prosthodontic options, but removable partial dentures (RPDs) are still widely used to replace missing teeth (4). In a clinical point of view, this type of prosthesis presents advantages such as the replacement of several teeth in a single prosthesis and it is easier to clean when compared to some fixed prostheses. On the other hand, RPDs can provide limited retention and stability due to their dual support system (5). Considering the free-end RPD, these aspects can be even worse, due to the prosthesis tendency to undergo rotational movements during function (6). Free-end removable prosthesis wearers may also present problems such as occlusal disharmony and pain of the soft tissue under the connector or denture base due to the displacement of RPD's distal extension (7). Furthermore, a technical and clinically satisfactory prosthesis is not necessarily a predictor of patient satisfaction, fulfilling the needs and expectations of the patients as regards the prosthesis (8). In this sense, patient-centered outcome measurements are important to better understand the effect of different treatments on patient's well-being and quality of life (9).

Clinical deficiencies of removable dentures, usually reported by patients, have sparked investigation of implantsupported RPDs $(7,10,11)$. Free-end RPDs combined with implant retainers are expected to improve retention and stability mainly because of the implants' direct action and their indirect action on bone, providing preservation of the bone level around the implants, especially important in the posterior edentulous areas $(4,10,11)$.

The use of mandibular free-end RPD with ball abutments as an alternative treatment for partially edentulous subjects has been intended for cases where an implant-supported fixed prosthesis cannot be installed due to anatomical or economic reasons $(7,11)$. This type of rehabilitation can be performed over smaller and/or shorter implants (4), because it requires less bone height than the one recommended for an implant-supported fixed prosthesis (12). It involves a simple technique and may improve retention, stability, load transmission (11) and chewing function (10). Despite these advantages, relatively few studies have investigated the effects of different treatment options on the OHROoL of partially edentulous patients (9). To the authors' knowledge, only one study (4) compared conventional RPD and implant-supported RPD in terms of OHROoL, showing a significant improvement on oral health following the implant's association to conventional RPD. However, in this former study (4), the results may be influenced by 
the presence of different RPD designs, including the RPD support in molars and pre-molars, for instance. It is known that partially edentulous patients with missing post-canine teeth present a serious impairment of chewing capacity (13) with possible consequences to their daily life. Thus, it is important to find out the impacts of different therapeutic interventions, such as conventional free-end RPDs and implant-supported RPDs, on the OHROoL of the patients presenting this extreme condition of tooth loss, which is the main objective of the present study.

\section{Material and Methods}

\section{Participants}

The present study included patients who sought surgical treatment at Piracicaba Dental School, University of Campinas (UNICAMP). These patients were part of a previous work (14) where they received fixed dental prostheses retained by implants in the mandibular arch. Subjects were required to present as inclusion criteria total maxillary and partial mandibular edentulism, presenting only the mandibulary canines and incisors, as well as sufficient bone height and volume in the mandibular molars region. These bone aspects were evaluated by panoramic indicated that 10 volunteers would be enough to detect a 10-point difference in the Oral Health Impact Profile (OHIP) questionnaire (power of $80 \%$ and an error probability of $5 \%$ ). Therefore, the study sample consisted of 12 volunteers (four men and eight women; mean age $62.6 \pm 7.8$ years). All clinical interventions and assessments were performed in accordance with ethical principles; the research protocol (\#011/2010) was approved by the Ethics Committee of Piracicaba Dental School., All volunteers gave their written consent to the study after detailed information was provided to them.

\section{Implant Placement and Evaluation Protocols}

Each participant received general dental treatment including basic periodontal therapy and tooth restoration procedures. Next, a conventional complete maxillary denture and a conventional mandibular free-end RPD were processed and installed by the same prosthetic technician and dentist. Cobalt-chromium (Co-Cr) alloy (DegussaHüls AG, Hanau, Germany) was used to fabricate the RPD frameworks, consisting of a lingual bar, circumferential clasps and lingual cingulum rests in the canines. The artificial teeth were assembled to enable bilateral balanced occlusion. After the mandibular free-end RPD was installed, dental visits were required for prosthesis adjustments.
Two months after this adaptation period, the OHIP-49 questionnaire was applied.

Subjects were then submitted to mandibular computed tomography (CT) aided by a surgical guide to determine appropriate implant lengths and position. In accordance with a standardized two-stage implant protocol (12), two implants (Neodent, Curitiba, Paraná, Brazil) were bilaterally installed in the first molar sites by a single dentist. The RPD was then adjusted and relined if needed to be used during the osseointegration period. After four months, 2 ball abutments (BA; Neodent) were added to the most posterior implants and the capsules were fitted to the mandibular free-end RPD acrylic base. To allow abutment placement, the RPD bases were worn out with carbide burs (Labordental Ltda., São Paulo, SP, Brazil). Acrylic resin (Jet; Artigos Odontológicos Clássico, São Paulo, SP, Brazil) was used to secure the implant attachment, or retainers. The mandibular free-end RPD with ball attachments was used for two months and OHRQoL was then assessed.

The Portuguese version of the OHIP-49 questionnaire - translated and adapted from the English version $(16,17)$ - was used to assess the participants' OHROoL. This questionnaire comprises 49 items assigned to seven domains: functional limitation; physical pain; psychological discomfort; physical disability; psychological disability; social disability; and handicap. Subjects were told to rate the frequency in which they had experienced the impact of each OHIP item in the past 2 months on a five-point Likertlike scale ( 4 = very often; 3 = fairly often; 2 = occasionally; $1=$ hardly ever; $0=$ never). 0 HIP scores ranging from 0 (very good $\mathrm{OoL}$ ) to 196 (very poor $\mathrm{OoL}$ ) were calculated.

\section{Statistical Analysis}

Shapiro-Wilk test revealed a non-parametric distribution of the data. The Wilcoxon signed-rank test was then used to evaluate differences between both tested prosthetic treatment conditions (RPDs with and without implant retainers). Statistical analyses were carried out using the SigmaStat software (version 3.5; Systat Software Inc., San Jose, CA, USA) at a significance level of 5\%.

\section{Results}

Table 1 shows the overall median of OHIP-49 and the medians of each of the seven OHIP-49 domains for each prosthetic treatment. The conversion of conventional RPD into implant-supported RPD by the association of ball abutments significantly improved the OoL of all participants, as indicated by a reduction in the total and domain scores observed in the present study.

The most frequent QoL concerns reported by the subjects after using both prosthetic devices tested are listed in Table 2. Scores for all concerns, except for 'food catching' (07), 
were found to be significantly reduced $(p<0.05)$.

\section{Discussion}

This prospective clinical trial, focusing on patients with extreme condition such as missing post-canine teeth, revealed increased $\mathrm{OHOoL}$ after the prosthetic treatment involving implant retainers combined with free-end RPDs. OHROoL can be assessed by several questionnaires $(16,17)$. However, it should be emphasized that OHIP is a widely used questionnaire, suitable for adults and partially edentulous patients (17).

Previous studies $(4,9,18,19)$ also revealed improvement in quality of life after implant therapy; however, none of them was conducted on patients with extreme condition of tooth loss such as the missing post-canine. Moreover, these previous studies encompassed clinical studies in which there was no pairing design $(9,19)$; either each patient received a different number of implants (18) or the dental pattern of the maxillary arch patients was not standardized (4). The present study assessed the same patient, before and after the conversion of a conventional RPD into an implant-supported RPD with the advantage of a very homogenous sample, consisting of subjects with similar clinical characteristics, the same number of teeth and similar type of prosthesis in both arches, which increased the power of the comparison between treatments.

Prosthetic rehabilitation generally improves QoL of patients, regardless of whether they have conventional or implants therapy $(5,20)$. Patients who receive implant-supported prostheses are usually more satisfied than those undergoing a conventional therapy (18). This is evident in studies comparing patients wearing conventional complete denture to those who had implant-supported complete dentures, which revealed similar OHIP-49 improvements, a condition associated with better OHRQoL after the use of implantbased prostheses $(19,21)$.

As regards partially edentulous patients, other authors $(4,9,20)$ also reported benefits towards implantsupported partial dentures. OHIP-49 mean values were found to be reduced as a conventional RPD was converted to an implant-supported RPD (4). In addition, strategic placement of implants under an existing removable partial or complete dental prosthesis also improves the masticatory function and food intake of partially edentulous patients $(14,22,23)$. All these benefits may be felt by the patient, explaining the substantial improvements on the OHIP-49 scores observed after the insertion of a single posterior implant to retain and stabilize a mandibular free-end RPD. Likewise, the present OHIP scores were in agreement with the volunteers' concern variable, which dropped significantly after use of implant- 
supported RPD, except the variable 'food catching'.

The persistent worry towards the variable 'food catching' in this study may be due to the removable nature of the conventional free-end RPD, even after the inclusion of implant's additional retention, which still allows food to be caught under the denture base. As food catching is more common among patients wearing removable prostheses (19), this could contribute to explain these specific data.

Several studies $(9,18,21,24)$ used OHIP tools to assess quality of life, including a number of participants quite greater than used in the present study. However, it is important to emphasize that this study's sample size was enough to evidence improvement in subject's oral health self-perception and $\mathrm{OoL}$ after use of mandibular free-end RPDs with ball attachment. Besides, due to the paired design of the present study, as well as the highly significant differences observed in the obtained data, and considering that the test power obtained for each OHIP domain was greater than $90 \%$, it is likely that increasing the sample size certainly would not change results.

It is important to highlight that the therapeutic approach used in the present study, improves the patients' self-perception towards OHROoL without extensive s surgical procedures, such as bone grafting. Moreover, $\approx$ this kind of treatment is less complicated compared to implant-supported fixed partial prostheses. Nevertheless, careful planning is crucial to ensure success and prevent or minimize future problems, such as periodontal and periimplant bone changes. In summary, the present results suggest that the strategic placement of osseointegrated implants in the posterior region of patients with postcanine missing teeth, significantly improves the quality of life besides increasing the retention and stability of conventional free-end RPD.

\section{Resumo}

Este estudo avaliou a qualidade de vida relacionada à saúde bucal (OVRSB) em indivíduos parcialmente dentados, apresentando perda extrema de dentes na região posterior com ausência de dentes póscaninos, comparando a reabilitação por meio de próteses parciais removiveis convencionais (PPRs) e PPRs implanto-suportadas. A OVRSB foi mensurada utilizando a versão brasileira do Oral Health Impact Profile (OHIP-49). Doze indivíduos apresentando edentulismo total maxilar e Classe I de Kennedy mandibular (idade média 62,6 $6 \pm 7,8$ anos) receberam primeiramente próteses totais maxilares e PPRs mandibulares convencionais de extremidade livre. Após dois meses de uso destas próteses, a QVRSB dos voluntários foi avaliada. Implantes osseointegrados foram bilateralmente instalados na região de primeiros molares inferiores $e_{\text {, }}$ após quatro meses, pilares do tipo bola foram instalados para suportar a extremidade livre da PPR. Após dois meses a QVRSB dos voluntários foi reavaliada. 0 teste pareado de Wilcoxon foi utilizado para avaliar as diferenças de QVRSB $(\alpha=0,05)$. Os resultados mostraram melhora em todos os domínios do OHIP-49 $(p<0,05)$ após a associação dos implantes à PPR. PPRs de extremidade livre mandibulares implanto-suportadas melhorou significativamente a OVRSB.

\section{Acknowledgements}

The São Paulo Research Foundation (FAPESP, \# 2010/12251-0) and the National Council for Scientific and Technological Development (CNPq, \# 144794-2010-1), Brazil, supported this research. The authors acknowledge the surgical assistance of Dr. Gabriela Mayrink Gonçalves and Professor Dr. Márcio de Moraes, from the Department of Oral Diagnostic, Piracicaba Dental School, University of Campinas - UNICAMP, Campinas, SP, Brazil.

\section{References}

1. Douglass CW, Shih A, Ostry L. Will there be a need for complete dentures in the United States in 2020? J Prosthet Dent 2002;87:5-8.

2. Miura H, Kariyasu M, Yamasaki K, Arai Y, Sumi Y. Relationship between general health status and the change in chewing ability: a longitudinal study of the frail elderly in Japan over a 3-year period. Gerodontology 2005;22:200-205.

3. Brennan DS, Singh KA. Dietary, self-reported oral health and sociodemographic predictors of general health status among older adults. J Nutr Heal Aging 2012;16:437-441.

4. Gates WD, Cooper LF, Sanders AE, Reside GJ, De Kok IJ. The effect of implant-supported removable partial dentures on oral health quality of life. Clin Oral Implants Res 2012;00:1-7.

5. De Freitas RFCP, de Carvalho Dias K, da Fonte Porto Carreiro A, Barbosa GA, Ferreira MA. Mandibular implant-supported removable partial denture with distal extension: a systematic review. J Oral Rehabil 2012;39:791-798.

6. Ben-Ur Z, Aviv I, Maharshak B. Factors affecting displacement of freeend saddle removable partial dentures. Quintessence Int 1991;22:2327.

7. Sato M, Suzuki Y, Kurihara D, Shimpo H, Ohkubo C. Effect of implant support on mandibular distal extension removable partial dentures: relationship between denture supporting area and stress distribution. J Prosthodont Res 2013;57:109-112.

8. De Lucena SC, Gomes SG, Da Silva WJ, Del Bel Cury AA. Patients' satisfaction and functional assessment of existing complete dentures: correlation with objective masticatory function. J Oral Rehabil 2011;38:440-446.

9. Swelem AA, Gurevich KG, Fabrikant EG, Hassan MH, Aqou S. Oral health-related quality of life in partially edentulous patients treated with removable, fixed, fixed-removable, and implant-supported prostheses. Int J Prosthodont. 2014;27:338-347.

10. Ohkubo C, Kobayashi M, Suzuki Y, Hosoi T. Effect of implant support on distal-extension removable partial dentures: in vivo assessment. Int J Oral Maxillofac Implants 2008;23:1095-1101.

11. Rodrigues RCS, Faria ACL, Macedo AP, de Mattos MDGC, Ribeiro RF. Retention and stress distribution in distal extension removable partial dentures with and without implant association. J Prosthodont Res 2013;57:24-29.

12. Cordaro L, Torsello F, Roccuzzo M. Implant loading protocols for the partially edentulous posterior mandible. Int J Oral Maxillofac Implants 2009;24:158-168.

13. van der Bilt A, Olthoff LW, Bosman F, Oosterhaven SP. Chewing performance before and after rehabilitation of pos-canine teeth in man. J Dent Res 1994;73:1677-1683.

14. Gonçalves TM, Campos CH, Gonçalves GM, de Moraes M, Rodrigues Garcia RC. Mastication improvement after partial implant-supported prosthesis use. J Dent Res 2013;92:189S-194S.

15. John MT, Slade GD, Szentpétery A, Setz JM. Oral health-related quality of life in patients treated with fixed, removable, and complete dentures 1 month and 6 to 12 months after treatment. Int J Prosthodont 2004;17:503-11.

16. Slade GD, Spencer AJ. Development and evaluation of the Oral Health Impact Profile. Community Dent Health 1994;11:3-11.

17. Pires $C P D A B$, Ferraz MB, de Abreu MHNG. Translation into Brazilian Portuguese, cultural adaptation and validation of the oral health impact profile (OHIP-49). Braz Oral Res 2006;20:263-268.

18. Pavel K, Seydlova M, Dostalova T, Zdenek V, Chleborad K, Jana Z, et al.. Dental implants and improvement of oral health-related quality of life. 
Community Dent Oral Epidemiol 2012;1:65-70.

19. Furuyama C, Takaba M, Inukai M, Mulligan R, Igarashi $Y$, Baba K. Oral health-related quality of life in patients treated by implant-supported fixed dentures and removable partial dentures. Clin Oral Implants Res 2012;23:958-962.

20. Fueki K, Kimoto K, Ogawa T, Garrett NR. Effect of implant-supported or retained dentures on masticatory performance: a systematic review. J Prosthet Dent 2007;98:470-477.

21. Harris D, Höfer S, O'Boyle CA, Sheridan S, Marley J, Benington IC, et al.. A comparison of implant-retained mandibular overdentures and conventional dentures on quality of life in edentulous patients: a randomized, prospective, within-subject controlled clinical trial. Clin
Oral Implants Res $2011 ; 24: 1-8$

22. Campos $\mathrm{CH}$, Gonçalves TM, Rodrigues Garcia RCM. Implant retainers for free-end removable partial dentures affect mastication and nutrient intake. Clin Oral Implants Res 2013;25:957-961.

23. Gonçalves TM, Campos CH, Rodrigues Garcia RC. Mastication and jaw motion of partially edentulous patients are affected by different implant-based prostheses. J Oral Rehabil 2014;41:507-514.

24. Özhayat EB, Gotfredsen K. Effect of treatment with fixed and removable dental prostheses. An oral health-related quality of life study. J Oral Rehabil 2012;39:28-36.

Received February 232015 Accepted July 20, 2015 